to account for Fitzhardinge's ${ }^{5}$ findings of a direct association of neurodevelopmental handicap with intrauterine growth retardation.

Understanding the mechanism or mechanisms whereby poor intrauterine growth makes infants of very low birth weight at risk of neurodevelopmental handicap extends beyond mere scientific curiosity: there are important clinical implications. If there is direct interference with brain growth obstetricians will be faced with the difficult dilemma of how long intrauterine life should continue once intrauterine growth retardation has been diagnosed. Should elective delivery by caesarean section be seriously considered, and, if so, when? Where there are no maternal contraindications to continuing the pregnancy, should more serious attempts be made to improve fetoplacental function, and therefore intrauterine growth, by treatment with heparin ${ }^{11}$ or hypertonic dextrose and amino-acid solutions ? $^{12}$ On the other hand, if, and as seems more likely, intrapartum asphyxia is the cause of later handicap in these babies then the emphasis must be on the delivery. Every effort must be made for this to take place in a unit where there are facilities for intrapartum monitoring and where the necessary medical skills are available to intervene in labour and to resuscitate the baby promptly should asphyxia have occurred.

${ }^{1}$ Calâme, A, and Prod'hom, L S, Schweizerische medizinische Wochenschrift, $1972,102,65$.

2 Davies, P A, and Tizard, J P M, Developmental Medicine and Child Neurology, 1975, 17, 3.

${ }^{3}$ Stewart, A, et al, in Major Mental Handicap: Methods and Costs of Prevention, Ciba Foundation Symposium 59 (new series), p 139. Elsevier, Excerpta Medica, 1978

4 Davies, P A, in Recent Advances in Paediatrics, no 5, ed D Hull, p 89. Edinburgh, Churchill Livingstone, 1976.

${ }^{5}$ Fitzhardinge, P M, et al, in Major Mental Handicap: Methods and Costs of Prevention, Ciba Foundation Symposium 59 (new series), p 139. Elsevier, Excerpta Medica, 1978.

6 Gross, S J, et al, American fournal of Diseases of Children, 1978, 132, 754

7 Marriage, K, and Davies, P A, Archives of Disease in Childhood, 1977, $52,176$.

${ }^{8}$ Gruenwald, P, Biology of the Neonate, 1963, 5, 215.

9 Chase, H P, et al, Pediatrics, 1972, 50, 403.

10 Dobbing, J, in Scientific Foundations of Paediatrics, ed J A Davis and $\mathrm{J}$ Dobbing, p 565. London, Heinemann, 1974.

11 Bonnar, J, Fournal of Clinical Pathology, 1974, 27, 514.

12 Beischer, N A, Medical fournal of Australia, 1975, 2, 379.

\section{The dilated upper urinary tract}

No aspect of urology has undergone such recent reappraisal as obstruction of the upper urinary tract. The orthodox view, that dilatation of the upper urinary tract in the absence of vesicoureteric reflux was synonymous with obstruction, has now been discarded in the face of convincing evidence that gross dilatation of the ureter or renal pelvis or both may occur in diseases in which no obstruction can be detected. ${ }^{12}$ In many instances this lesson was learnt the hard way from disappointing results of operating on these dilated but non-obstructed systems; occasionally, and worse, the unfortunate outcome of this pursuit of a will-o'-the-wisp was the creation of a real obstruction or even vesicoureteric reflux.

Investigation of disease of the upper urinary tract is centred on intravenous urography, but mistakes will continue to be made if urography alone is thought to be capable of giving all the answers. The urogram gives only a rough guide to renal function; often it cannot distinguish reliably between a large, flabby upper urinary tract and a tense obstructed one. That is not to say that obstruction cannot be diagnosed from a wellexecuted urogram, but simply that in equivocal or difficult cases it may be misleading. The problem is greater in chronic than in acute obstruction.

The search for better methods of diagnosis has led to study of the dynamics in the upper tract, since obstruction implies an impedance to flow or an increase in the pressure within the system to keep the usual flow of urine passing through. This approach has been fruitful: percutaneous studies of pressure and flow (under radiographic control) are now providing reliable and sometimes unexpected findings, and have been especially useful in managing difficult paediatric problems. ${ }^{34}$ These are, however, invasive procedures, so that inevitably departments of nuclear medicine have taken up the challenge of looking for alternatives. O'Reilly et $a l^{5}$ in Manchester believe that obstructed and non-obstructed dilated systems can be distinguished by comparing the renograms in the dehydrated and hydrated states. Nevertheless, they compared their initial results only with their findings at operation. Others who have compared the Manchester method with dynamic studies have found that even renography on hydrated patients can overdiagnose obstruction in those with greatly dilated upper tracts and underdiagnose it in those with early obstruction but minimal dilatation. ${ }^{2}$

A group from St Bartholomew's Hospital has compared three different ways of diagnosing obstruction in patients with equivocal hydronephrosis ${ }^{6}:$ firstly, the increase in size of the renal pelvis on a urogram after the administration of a diuretic; secondly, percutaneous dynamic studies; and, finally, renography. Their numbers were small, and in only 12 of their 20 patients could the results of all three studies be compared. Nevertheless, they contend that there is evidence of obstruction when the patient is given intravenous frusemide and the size of the renal pelvis increases by over a fifth of its size at 20 minutes after injection of contrast medium. The report does not state if any of the pelves collapsed down on an erect or postmicturition film-a sign often taken to indicate the absence of significant obstruction. A critical and longer look at this method is needed.

A new approach that emerged from this and a later study by the same group at St Bartholomew's is using radioactive isotopes to measure the "transit time" between the renal parenchyma and the collecting system. ${ }^{7}$ When obstruction has affected function (obstructive nephropathy) the parenchymal transit time is increased-apparently because increased retention of salt and water prolongs the intratubular luminal transit of the isotope. This method should overcome the problem of poor mixing in a very dilated system, but whether it is measuring obstruction or its subsequent effect on the kidney is not yet clear-for factors other than obstruction could alter the transit time. Nevertheless, undoubtedly after relief of obstruction the transit time returns towards normal.

These elaborate isotope techniques are at an early stage of development, and whether they will provide a reliable answer in all cases of equivocal obstruction remains to be seen. Meanwhile urodynamic techniques remain a standard against which they can be compared.

\footnotetext{
' Shopfner, C E, American fournal of Roentgenology, 1966, 98, 172

2 Whitaker, R H, British fournal of Urology, 1975, 47, 377

${ }^{3}$ Whitaker, R H, British fournal of Urology, 1973, 45, 15.

${ }^{4}$ Whitfield, H N, et al, British fournal of Urology, 1976, 48, 427.

5 O'Reilly, P H, et al, British Fournal of Urology, 1978, 50,76.

6 Whitfield, H N, et al, British fournal of Urology, 1977, 49, 615.

? Whitfield, H N, et al, British fournal of Urology, 1978, 50, 433.
} 